\title{
Identification, Job Satisfaction and Work Motivation among Tutors at the Open University of Israel
}

\author{
Ruth Beyth-Marom, Gal Harpaz-Gorodeisky \\ Aviad Bar-Haim, and Eti Godder \\ The Open University of Israel
}

\begin{abstract}
Tutors working for The Open University of Israel (OUI), a distance learning institution, are often the only academic staff who have direct contact with students. Their performance is therefore crucial for the university. The nature of their job, however, might hinder optimal performance: they are temporary and part time employees, and thus have low job security. Their academic freedom is limited and, in most OUI learning centers, they are professionally isolated. These factors can negatively affect tutors' organizational identification, job satisfaction, and motivation. This study is focused on two sets of variables that serve as possible predictors of identification, satisfaction, and motivation: (1) role perceptions (job importance and job richness); and (2) organizational attachment (relations with the university, attentiveness of the university and the university's appreciation of their work). Seventy-one $(n=71)$ tutors completed a general survey. Regression analysis and path analysis revealed that identification and job satisfaction were well predicted by job importance and organizational attachment, while work motivation was not. Theoretical and practical implications are discussed.
\end{abstract}

Keywords: Distance learning; tutors; organizational identification; job satisfaction; work motivation

\section{Introduction}

Course teams in distance learning universities share an important feature which distinguishes them from staff in conventional higher institutions. In a conventional university, academic courses are conducted by faculty members with the occasional aid of teaching assistants. They are responsible for both the course material and the teaching. On the other hand, in the Open University of Israel (OUI), as in some other distance learning institutions, there is a different division of labor. Senior faculty members develop the course material (textbooks, study guides, readings, etc.), which are designed didactically for self and distance learning. Generally, however, faculty members are not the people who teach the course. This is done, first and foremost, by the course material package itself, which includes exercises, add-on devices, Internet sites, and administrative instructions such as timetables and other useful guidelines. Instructional responsibilities rest on the shoulders of the course coordinator (CC), who runs the academic as well as the organizational aspects of the course, and coordinates the activities in the different tutorial groups, each run by a separate tutor. The CC prepares the tutorial outlines, assignments, and exams. When the course enrollment is small, the CC runs a single tutorial group or few of them. When enrollment is large and dispersed geographically, however, there are several or even 
Beyth-Marom, Harpaz-Gorodeisky, Bar-Haim, Godder

Identification, Job Satisfaction and Work Motivation among Tutors at the Open University of Israel

many tutorial groups. Thus, the CC has to recruit tutors, train them for the specific requirements of the course, monitor their academic and educational performance, and be responsible for updating their knowledge, skills, and abilities when the course material is renewed, upgraded, or changed.

Faculty members and course coordinators are permanent OUI employees and work on its main campus. Tutors are temporary OUI employees (their contract is renewed every semester) and perform their duties in their local OUI learning center. In contrast with their low job security and wages, and low level of academic freedom, these tutors responsibilities are numerous and in many courses they are "the face" of the university, as the only OUI staff with whom students meet and know directly. Therefore, we identify this group of tutors as strategically important for the quality and attractiveness of the university, but in the same vein as, potentially, a vulnerable link in the Open University's educational chain.

Job characteristics and the nature of relationships between the employee (tutors in the OUI in our study) and the organization (the OUI) are two sets of variables which are often studied in connection with satisfaction, identification with the organization, and motivation. Research studies on job characteristics rely on the well-known and well-researched theory of Hackman and Oldham $(1975 ; 1976)$ and their model of the relationships between core job characteristics, critical psychological states, and their impact on several affective, motivational, and performance outcomes (Fried and Ferris, 1987; Loher, Noe, Moeller and Fitzgerald, 1985; Taber and Taylor, 1990; Renn and Vandenberg, 1995) see endnote 1.They proposed that jobs which enable workers to exercise different skills and abilities (skill variety), to complete identifiable pieces of work (task identity), to apprehend the importance of the job (task significance), to plan the work and its space (autonomy), and which have a built-in feedback mechanism (feedback), lead to favorable results in terms of satisfaction, work motivation, and work performance. Another body of research in this context relates to job involvement (Kanungo, 1982), and work role centrality (Mannheim, Baruch and Tal, 1997). Work centered individuals have a high need for achievement, are satisfied with their job, and are more committed to their organization.

According to Hackman and Oldham's model (Hackman and Oldham, 1976), some characteristics of the tutors' job suggest a possible low potential for work motivation. Tutors have very little impact on the course material, course assignments, exams, and even the tutorials. Their job autonomy is relatively limited. The temporariness of their job may decrease their job centrality, motivation, and satisfaction. On the other hand, other characteristics of their job (skill variety and task significance) depend less on the organizational definition and may be more related to the tutors' perceptions.

Employees' relations with their employing organization are also well documented in many research studies. Among the most researched themes are identification with the organization, satisfaction, and work motivation. In a review on the correlates of perceived organizational support, Rhoades and Eisenberger (2002) demonstrated that perceived support, defined by how an organization values its employees' contribution and cares about their well being, is related to favorable outcomes for employees (job satisfaction, positive mood) and for the organization (commitment, performance).

Organizational identification and commitment are known to be positively related with contribution to the organization and job satisfaction (Mael and Ashforth, 1992; Meyer and Allen, 1997; Meyer, Stanley, Herscovitch and Topolnytsky, 2002), and negatively related with turnover intentions (Abrams, Ando and Hinkle, 1998; Mael and Ashforth, 1995; Ellemers, Spears and Doosje, 1997; Wan-Huggins, Riordan and Griffeth, 1998). Job satisfaction itself is expected to 
Beyth-Marom, Harpaz-Gorodeisky, Bar-Haim, Godder

Identification, Job Satisfaction and Work Motivation among Tutors at the Open University of Israel

grow as employees feel that they have enrichment potential in their job (LePine, Erez and Johnson, 2002; Organ and Ryan, 1995).

Competitive and high-performance organizations, such as some universities, expect their workforce to perform above and beyond their formal duties in return for more tangible and symbolic rewards and support, including appreciation and respect. Another dimension of these expectations for extra behavioral performance has recently been researched around the theme of Organizational Citizenship Behavior (OCB) (Borman and Penner, 2001; Organ and Ryan, 1995; Schappe, 1998). In a paper devoted to the causes of OCB, Rioux and Penner (2001) wrote: "Much of the current research on the causes of OCB either implicitly or explicitly assumes that engaging in such behavior is a reaction or a response to an individual's perceptions of his or her job and the organization for which he or she works" (p. 1306).

Since the tutors are almost the only academic staff in direct contact with students, their role perceptions, their relations with the university, and their organizational identification, motivation, and satisfaction are very important to the OUI. This concern is the raison d'etre for the present study. Its uniqueness is in applying concepts from job characteristics and organizational attachment theories to employees in the organizational context of a distance learning institution.

Two sets of predictor variables were used in this study: tutors' job characteristics and the nature of the attachment of the tutors to the university. We applied two notions of Hackman and Oldham's (1976) well-known scheme of job characteristics: perceived importance of the job (task significance in Hackman and Oldham's scheme) and its richness (skill variety in their scheme). Concerning "organizational attachment," we borrowed three variables from the OCB literature: the perceived relationship between the tutors and the university, the attentiveness of the university to tutors' needs or suggestions, and its appreciation of the tutors' work.

Thus, the predictor variables in our study were: job characteristics (perceived importance of the job, perceived richness of the job) and organizational attachment (relationship with the university, attentiveness of the university to tutors' needs/ suggestions, and the appreciation of tutors' work by the university - as perceived by the tutor). The three criterion variables were: identification with the university, job satisfaction, and work motivation (willingness to exert above and beyond duties).

\section{Method}

Seventy-one tutors $(n=71)$ (representing a response rate of 42 percent) from the Department of Education and Psychology completed a 107-item Likert-type questionnaire. Their mean age was 36 (compared to a mean age of 39 for all university tutors). 75.4 percent were females (compared to 61.3 percent for all university tutors). The questionnaire included questions regarding job perception, relationship with the university in general and with different departments in particular, amount and quality of pre-training and on-the-job training, identification with the organization, satisfaction and motivation, as well as some background questions regarding gender, age, and length of service. We used the data from this general survey for the present study see endnote 2. For each of the variables of interest there were one or more questions. 
Beyth-Marom, Harpaz-Gorodeisky, Bar-Haim, Godder

Identification, Job Satisfaction and Work Motivation among Tutors at the Open University of Israel

\section{Predictor Variables}

\section{Job characteristics:}

(1) Importance of the job: "How important is your job as a tutor to you?" (from "1-not at all" to "5-very much").

(2) Richness of the job: The main responsibility of tutors is the teaching of the course material. However, there are three additional tasks in which tutors might be involved: training for learning skills, counseling students in their curriculum, and representing the university. For each of the additional tasks, tutors were asked "To what extent do you feel you have to . . . (train learning skills/ counsel students/ represent the university)" (from "1-little" to "3-very much"). Job richness was defined as the sum of the scores of the three items (values score from 3 to 9 ).

\section{Organizational attachment:}

(3) Relationship with the university: "How would you define your relation with the university?" (from "1-not good at all" to "5-very good") see endnote 3.

(4) Attentiveness of the university: "To what extent do you feel the university is attentive to your needs?" (from "1-not at all" to "5-very much").

(5) Appreciation by the university: "To what extent does the university appreciate your work as a tutor?" (from "1-not at all" to "5-very much").

We did not combine the predictors into composite indices. However, we calculated reliability for the three items of organizational attachment (Cronbach's Alpha $=.866$ ) and the two job characteristics items (which did not compromise any reliable scale).

\section{Criterion Variables}

(6) Identification with the university: "To what extent do you identify with the university?" (from "1-not at all" to "5-very much").

(7) Job satisfaction: "Are you satisfied with your job as a tutor?" (from "1-not at all" to "5-very much").

(8) Work motivation (willingness to exert above and beyond duties): As already mentioned, tutors are responsible only for the tutorial meetings and the scoring of assignments. However, we also asked them about their willingness to be involved in six additional tasks which are normally the duty of the CCs: composing assignments, specifying criteria for marking the assignments, composing exams, specifying criteria for marking the exams, marking the exams, and organizing the online activity on their course Internet site. For each of the six listed tasks they could choose one of three answers: "1- don't want", "2- want", "3- want very much". For each aspect a dichotomous variable was defined: 0 (for those who chose the first category) and 1 (for those who chose either the second or the third category). Willingness to exert more was defined as the sum of the answers to the six separate questions, thus a variable in the range from 0 to 6 . 
Beyth-Marom, Harpaz-Gorodeisky, Bar-Haim, Godder

Identification, Job Satisfaction and Work Motivation among Tutors at the Open University of Israel

\section{Results}

Table 1 presents means, standard deviations, and correlations of the predictor and criterion variables in the study.

Table 1. Descriptive Statistics and Correlations for Study Variables

\begin{tabular}{|c|c|c|c|c|c|c|c|c|c|}
\hline Variable & $\overline{\mathrm{M}}$ & SD & 1 & 2 & 3 & 4 & 5 & 6 & 7 \\
\hline 1. Relation & 3.5 & 1.0 & - & & & & & & \\
\hline 2. Attentive & 3.0 & 1.0 & $0.73^{* *}$ & - & & & & & \\
\hline 3. Appreciate & 3.2 & 1.0 & $0.61^{* *}$ & $0.71^{* *}$ & - & & & & \\
\hline 4. Job Import. & 4.3 & 0.7 & $0.38 * *$ & 0.23 & $0.42^{* *}$ & - & & & \\
\hline 5. Job Richn. & 6.1 & 1.8 & $0.23^{* *}$ & 0.14 & $0.28 *$ & 0.18 & - & & \\
\hline 6. Identification & n 3.3 & 1.0 & $0.69 * *$ & $0.54^{* *}$ & $0.52^{* *}$ & $0.47^{* *}$ & $0.33^{* *}$ & - & \\
\hline 7. Job Satisf. & 4.1 & 0.8 & $0.56^{* *}$ & $0.53 * *$ & $0.55^{* *}$ & $0.43^{* *}$ & 0.10 & $0.50^{* *}$ & - \\
\hline 8. Motivation & 4.6 & 1.7 & 0.18 & 0.14 & 0.23 & 0.06 & $0.24^{*}$ & 0.09 & 0.12 \\
\hline
\end{tabular}

As to job characteristics, tutors ranked their job as relatively high in importance. They defined their job in broad terms by adding, on average, two additional tasks to their formal duties (of the three presented to them). Concerning the second set of predictor variables (relation with the university, perceived attentiveness of the university and its perceived appreciation of the tutor's job) — tutors chose (on average) the middle rank.

\section{Univariate Analysis: A Regression Model}

First we examined the relationships between each of the three criterion variables and the five predictors in a univariate enter regression analysis. Identification and satisfaction of the OUI tutors are well predicted by their job characteristics and organizational attachment (R square of .564 and .461 respectively). The third criterion variable, work motivation, however, is poorly explained by the univariate regression (see Tables 2, 3, and 4).

In terms of unique effects (standardized Bs or betas), we find that only relations with the university, job importance, and job richness - as perceived by tutors, and only for identification - have a substantial, positive, and significant power. This means that in a univariate model our predictors are quite weak in explaining satisfaction and work motivation; but three of them (from both groups of the predictor variables) have reasonable effects on organizational identification. 
Beyth-Marom, Harpaz-Gorodeisky, Bar-Haim, Godder

Identification, Job Satisfaction and Work Motivation among Tutors at the Open University of Israel

Table 2. A Univariate Regression Analysis for variables predicting "Identification with the university."

\begin{tabular}{|c|c|c|c|c|c|}
\hline $\mathbf{R}$ & $\begin{array}{l}R \\
\text { Square }\end{array}$ & $\begin{array}{l}\text { Adjusted } \\
\text { R Square }\end{array}$ & $\begin{array}{l}\text { Std.Error of } \\
\text { theEstimate }\end{array}$ & $F(5,65)$ & Sig. \\
\hline .751 & .564 & .529 & .696 & 16.028 & $<.001^{*}$ \\
\hline & \multicolumn{2}{|c|}{$\begin{array}{l}\text { Un-standardized } \\
\text { Coefficients }\end{array}$} & \multicolumn{3}{|c|}{ Standardized Coefficients } \\
\hline (Constant) & $\begin{array}{l}\text { B } \\
-.819\end{array}$ & $\begin{array}{l}\text { Std. Error } \\
.597\end{array}$ & Beta & \begin{tabular}{|l}
$T$ \\
-1.371
\end{tabular} & $\begin{array}{l}\text { Sig } \\
.175\end{array}$ \\
\hline Relation & .522 & .136 & .498 & 3.852 & $<.001^{*}$ \\
\hline Attentiveness & .084 & .151 & .080 & .556 & .580 \\
\hline Appreciation & .005 & .134 & .005 & .040 & .968 \\
\hline Job importance & 325 & .147 & .216 & 2.209 & $.031^{*}$ \\
\hline Job richness & .100 & .049 & .184 & 2.058 & $.044 *$ \\
\hline
\end{tabular}

Table 3. A Univariate Regression Analysis for variables predicting "Job satisfaction."

\begin{tabular}{|c|c|c|c|c|c|}
\hline $\mathrm{R}$ & $\begin{array}{l}\mathrm{R} \\
\text { Square }\end{array}$ & $\begin{array}{l}\text { Adjusted } \\
\text { R Square }\end{array}$ & $\begin{array}{l}\text { Std. Error of } \\
\text { the Estimate }\end{array}$ & $F(5,65)$ & Sig \\
\hline 679 & .461 & .418 & .658 & 10.607 & $<.001^{*}$ \\
\hline & \multicolumn{2}{|c|}{$\begin{array}{l}\text { Unstandardized } \\
\text { Coefficients }\end{array}$} & \multicolumn{3}{|c|}{ Standardized Coefficients } \\
\hline (Constant) & $\begin{array}{l}\text { B } \\
1.101\end{array}$ & $\begin{array}{l}\text { Std. Error } \\
.580\end{array}$ & Beta & $\begin{array}{l}\mathrm{T} \\
1.897\end{array}$ & $\begin{array}{l}\text { Sig } \\
.062\end{array}$ \\
\hline Relation & .245 & .130 & .266 & 1.888 & .064 \\
\hline Attentiveness & .147 & .142 & .163 & 1.034 & .305 \\
\hline Appreciation & .208 & .126 & .235 & 1.649 & .104 \\
\hline Job importance & 249 & .137 & .196 & 1.810 & .075 \\
\hline Job richness & -.018 & .049 & -.035 & -357 & .722 \\
\hline
\end{tabular}


Beyth-Marom, Harpaz-Gorodeisky, Bar-Haim, Godder

Identification, Job Satisfaction and Work Motivation among Tutors at the Open University of Israel

Table 4. A Univariate Regression Analysis for variables predicting "Job motivation."

\begin{tabular}{|c|c|c|c|c|c|}
\hline $\mathbf{R}$ & \begin{tabular}{|l|}
$\mathbf{R}$ \\
Square
\end{tabular} & $\begin{array}{l}\text { Adjusted } \\
\text { R Square }\end{array}$ & $\begin{array}{l}\text { Std.Error of } \\
\text { theEstimate }\end{array}$ & $\mathrm{F}(5,65)$ & Sig. \\
\hline \multirow[t]{2}{*}{271} & .073 & -.001 & 1.50040 & 982 & .436 \\
\hline & \multicolumn{2}{|c|}{$\begin{array}{l}\text { Unstandardized } \\
\text { Coefficients }\end{array}$} & \multicolumn{3}{|c|}{ Standardized Coefficients } \\
\hline (Constant) & $\begin{array}{l}\text { B } \\
2.950\end{array}$ & $\begin{array}{l}\text { Std. Error } \\
1.290\end{array}$ & Beta & 86 & $\begin{array}{l}\text { Sig. } \\
.026^{*}\end{array}$ \\
\hline Relation & .125 & .300 & .081 & & .679 \\
\hline Attentiveness & -.120 & .332 & -.079 & & .719 \\
\hline Appreciation & .302 & .289 & .202 & 43 & .301 \\
\hline Job importance & -.192 & .311 & -.086 & 18 & .539 \\
\hline Job richness & .128 & .105 & .159 & 219 & .227 \\
\hline
\end{tabular}

\section{Multivariate Analysis: A Path Model}

In this section, we present a multivariate attempt to decipher the pattern of relationships of the criterion and predictor variables by a recursive path analysis, using the AMOS 5.0 algorithm for the structural equation models. As is well known, path models cannot establish the truth of a pattern of relationships; they can only examine the goodness of fit between hypothesized models and empirical data. However, since it is possible in principle to find more than a single solution to a relationships pattern (that is, a solution with reasonable goodness of fit), we still need to validate the findings of a path model by the context and content of the subject matter.

In our case of three criterion variables and five predictor variables, or in terms of path analysis, exogenous and endogenous variables, the only model with acceptable goodness of fit index (GFI and AGFI) and insignificant Chi Square is shown in Figure 1 and the following goodness-of-fit results see endnote 4.

Table 5. Goodness-of-fit results

\begin{tabular}{|l|l|l|l|l|l|l|l|}
\hline Goodness of Fit & NPAR & CMIN & DF & P CMN/DF & GFI & AGFI \\
\hline Our model & 33 & 1.562 & 3 & 0.668 & 0.521 & 0.994 & 0.949 \\
\hline Saturated model & 36 & 0.000 & 0 & & & 1.000 & \\
\hline The model is recursive and estimation is by Generalized L east Squares \\
\hline Chi-square = 1.562 (minimum was achieved) Degrees of freedom = 3 Probability level = 0.668 \\
\hline
\end{tabular}


Figure 1. A path model of the effect of perceived organizational attachment and perceived job characteristics on organizational identification, job satisfaction, and motivation.

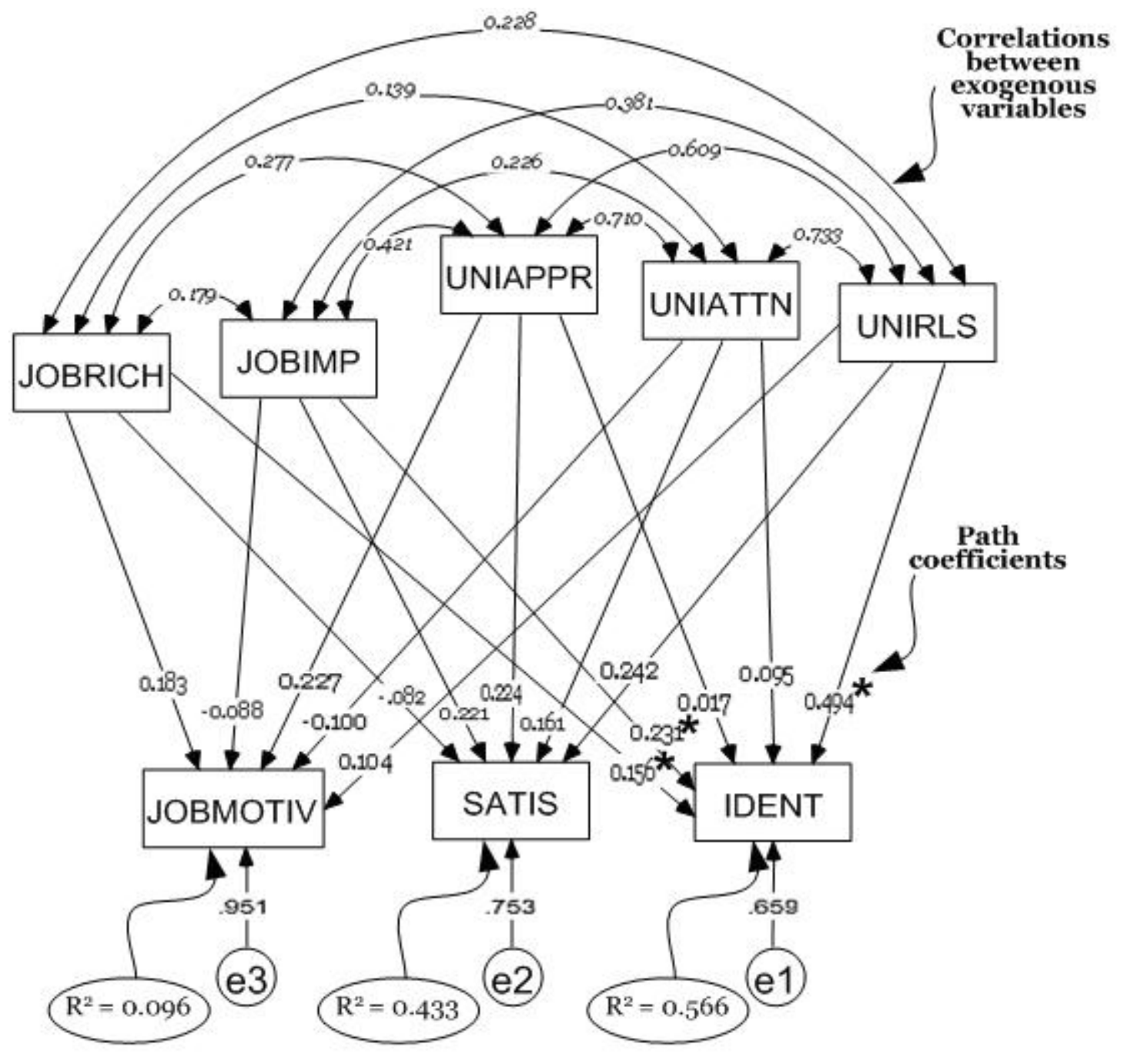

* Significant at .05 level

Prior to interpreting the model, a short reference to possible other models is required. We cannot show all the unfitted models that we tested (most of them were trials with different technical configurations of the residual terms). A report of two major alternatives, however, is in place:

(a) Criteria (work motivation, job satisfaction, and identification with the university) were predicted by perceived organizational attachment (relationship with the university, attentiveness of the university, and appreciation by the university), mediated by perceived job characteristics (importance and richness of the job). This model has an acceptable level of goodness-of-fit. Our final model, however, is better both in terms of goodness-of-fit and in terms of parsimony - e.g., there is no added information in this model beyond the simpler mode, that is obtained from the indirect effects of the predictors. The direct effects are exactly as those in the simpler model.

(b) Criteria were predicted by perceived job characteristics, mediated by perceived organizational attachment. This model has an unacceptable level of goodness-of-fit, and must be rejected. 
Beyth-Marom, Harpaz-Gorodeisky, Bar-Haim, Godder

Identification, Job Satisfaction and Work Motivation among Tutors at the Open University of Israel

Thus, we did not find a better alternative path model for this set of variables; therefore, in this particular case, we can focus on the interpretation of the better model. The relationship pattern revealed in the univariate analysis is basically the same in this multivariate analysis. As in the single regression analyses, also in the path analysis, we find that identification with the university and job satisfaction are well predicted by organizational attachment and job characteristics (R square of .566 and .433 respectively). Here too work motivation is poorly explained by the exogenous variables ( $\mathrm{R}$ square of .096). In terms of path coefficients (betas), we find that only relations with the university, job importance, and job richness, have some positive and significant power (beta $>$.22), and this mainly on identification.

The path analysis adds some further information about the relationships between the exogenous and endogenous variables. First, it reveals strong correlations among most of the exogenous variables (yet, not too strong to establish multi-colinearity). We find these high correlations especially in the organizational attachment set and job importance. It seems that job importance is perhaps an indicator of organizational prestige and attachment, as well as a characteristic of the job itself.

Support for this conclusion is obtained from a series of reliability tests on these four items (Cronbach's Alpha $=.818$ ) and on the three items of organizational attachment (Cronbach's Alpha $=.866$ ) - figures which are fairly closed see endnote 5 .

It also supports the importance of the organizational attachment set over the job characteristics set in predicting identification and satisfaction. This finding, which we see in the univariate regressions as well, is fine tuned in the path analysis when we include the effects of the error terms of the exogenous variables (e1, e2 and e3). Then we get a relatively lower effect of the error term e1 of the well explained identification variable, and a higher effect of the error term e3 of the poorly explained job importance variable.

\section{Discussion}

OUI tutors are often the only academic staff who have direct contact with students. Their performance is therefore crucial for the university. Their academic qualifications can be monitored by strict selection and training processes. Their behavior, however, is also influenced by other factors such as organizational identification, job satisfaction, and motivation, which cannot easily be managed and need vigorous academic leadership on the part of the university, and a sensitive and efficient response to the needs of this special group of temporary employees.

Two sets of variables were chosen as possible predictors of organizational identification, job satisfaction, and motivation (defined as willingness to do more). The perceived job characteristic set included "perceived job importance" and "perceived job richness." Tutors ranked their job as relatively high in its importance (a mean of 4.3 on a 1-5 Likert-type question). Although their main job is to instruct students during the tutorials, most tutors defined their job more broadly, adding on average two additional tasks to their formal duties.

The second set of predictor variables which was chosen focused on the organizational attachment of tutors. They were specifically asked about the quality of their relation with the university, about the attentiveness of the university to their needs, and about their perception of the university's appreciation of their work as tutors. For all three variables, the average rank chosen by tutors was 3 (the middle rank).

In spite of their low security, low level of academic freedom, low job centrality and isolation (not being in the main university campus), tutors perceive their job as important and "rich." These 
encouraging results (from the university's point of view) might be an outcome of two opposing characteristics of the tutors' job. On the one hand, tutors' job autonomy is very limited. On the other, they are the main and often the only university representatives in contact with students; therefore their power and authority, and thus autonomy, is actually high. The university delegates its power to tutors, thus enabling them to respond to students' pedagogical and administrative questions and needs. This delegation of power, however, is strictly controlled by the university, allowing the tutors very little flexibility. It seems that this delegation of power and the fact that for the students "the tutor is the university" influence the tutors' perceptions regarding their job importance and richness.

The regression analysis, as well as the path analysis, reveal that identification and job satisfaction are well predicted by job importance and organizational attachment, while work motivation is not. Thus, the tutors' identification with the university, and their job satisfaction, are sensitive to the quality of the relationship with the university, to the attention of the university, to the appreciation of their work and to their job importance.

The path analysis adds more information, especially regarding the correlations between the predictor variables. The three variables in the organizational attachment set are highly correlated, while for the two variables in the job characteristics set the correlation are much lower. Despite our division of the predictor variables into two sets, their inter-correlations reveal some overlap: perceived job importance is correlated more with variables in the organizational attachment set than with perceived job richness. Thus, perceived job importance increases as tutors feel the university is sensitive to their needs and appreciates their work.

It should be in the interest of the university to increase job satisfaction and organizational identification, as both have an impact on work performance (Meyer et al., 2002). Increasing the university attachment variables should, according to the results, contribute to such a rise. At a relatively low cost, the university can take measures to improve the relationship between the tutors and the university: for example, inviting tutors to special university events normally open only to permanent employees; listening more frequently to their problems and needs via surveys (like those given to students); enabling those who are interested to undertake additional tasks (e.g., composing assignments); and giving periodic feedback regarding various aspects of their job (e.g., visit a tutorial session, review their marking of assignments). These steps (some of which have already been taken by the university) might also improve the tutors' feelings about the university's appreciation of their work, its attentiveness to their needs, and its perception of the importance of their job.

We used tutors' responses regarding their willingness to do more, as an indicator of their job motivation. This variable, however, did not correlate substantially with any of the other criterion or predictor variables (contrary to what was expected based on the relevant literature). One reason for the present results might be the fact that tutors assumed that the extra duties suggested in the questionnaire would give them extra payment. This might also explain the relatively high average score on this variable - tutors were willing to do between four to five additional tasks (out of the six listed). Willingness to do additional work for extra money does not necessarily indicate high job motivation. Nevertheless, taking part in additional instructional duties (e.g., writing assignments and exams), can increase skill variety in Hackman and Oldham's (1975; 1976) terms, interest in the job and involvement, all contributory factors to job satisfaction and motivation.

The instructional team in a distance learning university such as the OUI, has a unique structure which has repercussions on the job definition and characteristics of the team members. In certain configurations, tutors' job characteristics have a potential for work alienation and its manifest and latent signs of dissatisfaction, low motivation and low morale. These might affect tutors' 
Beyth-Marom, Harpaz-Gorodeisky, Bar-Haim, Godder

Identification, Job Satisfaction and Work Motivation among Tutors at the Open University of Israel

performance and the way they represent the university when in direct contact with students. It is therefore very much in the interest of the OUI to strengthen and improve its relations with this segment of its workforce. The survey on which the present study was based, was a first step in an effort to open a line of dialogue between the tutors and the university. We used data from this survey to explore some of the potential sources of alienation, and through a path model and a regression analysis we were able to identify some of the factors which can be managed skillfully to increase satisfaction, motivation and identification with the university.

The suggested model, of course, needs further elaboration and testing in future surveys. Expansion should be made by enlarging the sample, taking the whole population of tutors in the OUI (from all academic departments). The present sample (from the Education and Psychology department) is relatively young (a mean of 36 in contrast to a mean of 39 for all OUI tutors) and contains more females (75.4 percent in contrast to 61.3 percent). It would be interesting to see if differences in these demographic variables will affect the suggested model. Testing and elaboration of the model should also be done in future surveys by using standard scales for the model's exogenous and endogenous variables.

\section{References}

Abrams, D., Ando K., and Hinkle, S. (1998). Psychological Attachment to the Group: Crosscultural differences in organizational identification and subjective norms as predictors of workers' turnover intentions. Personality and Social Psychology Bulletin 24(10), 1027 1039.

Allen, N. J., and Meyer, J. P. (1990). The measurement and antecedents of affective, continuance and normative commitment to the organization. Journal of Occupational Psychology 63(1), 1 - 18.

Borman, W. C., and Penner, L. A. (2001). Citizenship Performance: Its nature, antecedents, and motives. In B. W. Roberts \& R. Hogan (Eds.) Personality Psychology in the Workplace (pp. 45-61). Washington, DC.: American Psychological Association.

Ellemers, N., Spears, R., and Doosje, B. (1997). Sticking Together or Falling Apart: In-group identification as a psychological determinant of group commitment versus individual mobility. Journal of Personality and Social Psychology 72(3), 617-626.

Fried, Y., and Ferris, G.R. (1987). The Validity of the Job Characteristics Model: A review and meta-analysis. Personnel Psychology 40(2), 287 - 322.

Hackman, J. R., and Oldham, G. R. (1975). Development of the job diagnostic survey, Journal of Applied Psychology 60(2), 159 - 170.

Hackman, J. R., and Oldham, G. R. (1976). Motivation Through the Design of Work: Test of a theory. Organizational Behavior and Human Performance 16, 250 - 279.

Kanungo, R. N. (1982). Work Alienation: An integrative approach. Westport, CT.: Praeger.

LePine, J. A., Erez, A., and Johnson, D. E. (2002). The Nature and Dimensionality of Organizational Citizenship Behavior: A critical review and meta-analysis. Journal of Applied Psychology 87(6), 52 - 65. 
Loher, B. T., Noe, R. A., Moeller, N. L., and Fitzgerald, M. P. (1985). A meta-analysis of the relation of job characteristics and job satisfaction. Journal of Applied Psychology 70(2), $280-289$.

Mael, F. A., and Ashforth, B. E. (1992). Alumni and Their Alma Mater: A partial test of the reformulated model of organizational identification. Journal of Organizational Behavior 13(1), 103 - 123.

Mael, F. A., and Ashforth, B. E. (1995). Loyal From Day One: Biodata, organizational identification and turnover among new comers. Personnel Psychology 48(2), 309 - 333.

Mannheim, B., Baruch, Y., and Tal, J. (1997). Alternative models for antecedents and outcomes of work centrality and job satisfaction of high-tech personnel. Human Relations 50(12), 1537 - 1562.

Meyer, J. P., and Allen, N. J. (1997). Commitment in the Workplace: Theory, research and application. Thousand Oaks, CA.: Sage Publications.

Meyer, J. P., Stanley, D. J., Herscovitch, L., and Topolnytsky, L. (2002). Affective, Continuance, and Normative Commitment to the Organization: A meta-analysis of antecedents, correlates, and consequences. Journal of Vocational Behavior 61(1), 20 - 52.

Mowday, R., Steers, R., and Porter, L. (1979). The measurement of organizational commitment. Journal of Vocational Behavior 14(3), 224 - 247.

Organ, D. W., and Ryan, K. (1995). A meta-analytic review of attitudinal and dispositional predictors of organizational citizenship behavior. Personnel Psychology 48(2), 775 - 802.

Renn, R. W., and Vandenberg, R. J. (1995). The critical psychological states: an underrepresented component in job characteristics model research. Journal of Management 21(2), 279-303.

Rhoades, L., and Eisenberger, R. (2002). Perceived Organizational Support: A review of the literature. Journal of Applied Psychology 87(4), 698 - 714.

Rioux, S. M., and Penner, L. A. (2001). The Causes of Organizational Citizenship Behavior: A Motivational analysis. Journal of Applied Psychology 86(6), 1306 - 1314.

Schappe, P. (1998). The influence of job satisfaction, organizational commitment, and fairness perceptions on organizational citizenship behavior. The Journal of Psychology 132(3), $277-290$.

Taber, T. D., and Taylor, E. (1990). A review and evaluation of the psychometric properties of the job diagnostic survey. Personnel Psychology 43(3), 467 - 500.

Wan-Huggins, V. N., Riordan, C. M., and Griffeth, R. W. (1998). The development and longitudinal test of a model of organizational identification. Journal of Applied Social Psychology 28(8), 724 - 749. 
Beyth-Marom, Harpaz-Gorodeisky, Bar-Haim, Godder

Identification, Job Satisfaction and Work Motivation among Tutors at the Open University of Israel

\section{Endnotes}

1. See the application of Hackman and Oldham's model to distance learning systems in the work done at the Laboratory for Integrated Learning and Technology (LILT) of Illinois State University:

http://lilt.ilstu.edu/saskers/thesis/theoretical background.htm

Also, a short literature review and the use of a path model to examine their model, see: http://www.chrms.org/library/critic/critic1a.htm

2. As we used the general university survey for our study, we did not utilize standard measures for job characteristics (e.g., measures used by Hackman and Oldham) and for organizational attachment - e.g., questionnaires used by Mowday, Steers and Porter (1979) or Allen and Meyer (1990).

3. It should be noted that "the university" is perhaps represented to the tutors by the course coordinator and a few other role incumbents in the psychology department. They are rarely exposed to the full activities and behavior of the "university," or even to those the psychology department. They are dispersed geographically, and meet each other only infrequently in the university main campus.

4. There are many tests of goodness of fit. We used two of the most common, GFI, and the Chi Square test (fitted models should have insignificant Chi Square).

5. When we add the fifth item to the analysis, JOBRICH, Cronbach's Alpha drops to .680. The two job characteristics, JOBIMP and JOBRICH, do not comprise any reliable scale.

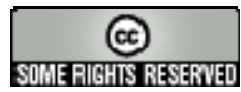

